the perineal wound. A thin splinter of stone was found imbedded in the tissues here and was removed.

Six weeks after the operation the perineal fistula was excised, its walls were sewn together, and the bladder was drained by catheter for three days. Two months after the operation the patient had partial control and passed two fairly vigorous streams from his urethra and the fistula respectively. The urine was cloudy, faintly acid, and contained a little albumin. A week later he insisted on going home. He had had news that his family, who live in a distant village, believed him to be dead; and he wished to correct this impression personally.

On May 11th, three and three-quarter months after the operation, the patient was fetched from his home for inspection. The perineal fistula was healed. There was a little bulging of the suprapubic scar, which he said was not increasing in size. His only disability was that when he walked about some urine dripped from his penis, and he had contrived to sling a little tin under it to keep him dry. When he lay down he could hold his urine and pass it voluntarily. The urine was cloudy and acid. The bladder was contracted and free from stone. He seemed in excellent health and spirits and had gained 12 pounds in weight.

The fragments of stone collected weighed 31.4 ounces damp and $30 \cdot 7$ ounces dry. On piecing them together it was clear that a good many had been lost. I think the entire stone must have weighed at least 32 ounces. By fitting together the blocks of the outer layer it was possible to reconstruct the shell which has been filled with plaster and presented to the Museum of the Royal College of Surgeons of England. It measures $4 \frac{1}{2} \times 3 \frac{3}{4} \times 2 \frac{3}{4}$ inches and shows three shallow transverse grooves due to bands on the bladder wall, as is usual in very large stones. ${ }^{1}$ The outer layer is about half an inch thick, smooth, and white like alabaster; it is composed of calcium phosphate. The inside of the stone is brown and composed of urates.

Mr. H. Littlewood in THE LANCET of May 11th, 1907, p. 1315, gave a list of the largest stones which had been successfully removed up to that date. The largest was removed in this hospital by Mr. H. M. N. Milton in 1893. It weighed $34 \frac{1}{2}$ ounces and was extracted whole by abdominal section. The bladder did not regain any power of expulsion and was drained by fistula. The patient recovered sufficiently to walk about out of doors, but he died after two and a half months from kidney disease. The second largest given is a case of Sir Thomas Smith; the stone weighed $24 \frac{1}{2}$ ounces and was removed entire by a suprapubic incision. Recovery was complete.

As regards the method of operation lithotrity was useless. I tried the lithotrite on the reconstructed stone and it failed to grip it; moreover, the stone seemed much too hard to be cracked in this way. But Mr. Milton has crushed a stone weighing 452 grammes, ${ }^{2}$ and there is no a pror $i$ reason why even bigger ones should not be crushed. At any rate my attempts resulted in no harm beyond the waste of time.

When lithrotrity and perineal crushing failed the choice lay between an abdominal section and the use of a chisel. A discussion on the merits of abdominal section will be found in ThE LANCET of Dec. 1st, 1900. Mr. Milton removed his record stone in this way, and an account of his brilliant operation was published in THE LANCET of Sept. 16th, 1893, p. 687. But in the hands of less experienced and less skilful surgeons I think that some method which does not involve the simultaneous opening of a septic bladder and the peritoneum will be found to carry with it less risk to the patient. Moreover, the very extensive crucial incisions necessary for extraction may very well interfere with the recovery of the power of the bladder.

The dangers of breaking up a stone with the chisel are not, I think, very great, and are certainly less the bigger the stone. With large stones their inertia and extent of surface act as safeguards, while a stone can be cracked by sharp light taps just as readily as by heavy blows. In some seaside resorts where the geological formation favours this kind of sideshow there are performers who demonstrate these principles by cracking rocks on one another's chests with a sledge-hammer.

Mr. Walter Rivington ${ }^{3}$ broke up an encysted stone weighing

$$
1 \text { Herbert Milton: The Lavcer, April 25th, 1896, p. } 1131 .
$$$$
2 \text { F. Milton : THE LANCET, Oet. 1st, 1904, p. } 949
$$

- Transactions of the Royal Merlical and Chirurgical Society, vol. Ixix., p. 360 .
23 ounces with a hammer and chisel, and Mr. Hurry Fenwick, who assisted at that operation, has since employed the same method for smaller stones, which must require far greater skill and nicety. ${ }^{4}$ A thin sharp osteotome is better than a chisel and easier to manage.

A perineal opening, besides being a great help in extraction, is essential for the after-treatment. ${ }^{\bar{b}}$ The drainage is better, and instead of the damaged tissues above the pubes being kept in a bath of septic urine they are dry from the start. I recently removed a stone weighing 370 grains (greatest circumference four and a half inches) from a child, aged four years, by a suprapubic incision. The child was very ill at the time. The peritoneum was not opened at the operation, but four days later a round patch of the size of a sixpence sloughed away and the child died from peritonitis. If the wound had been kept dry by a perineal drain I do not think the patch would have sloughed or that the child would necessarily have died if it had. These considera. tions do not apply to the ordinary suprapubic lithotomy, but become of importance when the stone is big, the urine foul, and the tissues of poor resisting power.

The ultimate results of operations for very large stones must always depend far less on the method or the surgeon than on the state of the patient's kidneys. This is not easy to estimate in such cases, nor is it practically important to attempt it, for the condition will not improve while the stone remains, and every patient who is not actually dying ought to be operated on. Spinal anæsthesia may perhaps diminish the risk; my limited experience of it has been encouraging. But as regards the margin which is left to the surgeon for good or evil in such cases, I submit that a piecemeal extraction with osteotome and mallet above the pubes, with free perineal drainage, offers a better chance than any other method.

Cairo.

\section{THE DIAGNOSIS OF DISEASES OF THE STOMACH AND INTESTINES BY THE X RAYS.}

By C. J. MORTON, M.D. EDIN., SURGICAL RADIOGRAPHER TO GUY'S HOSPITAI.

IMPROVED methods of examination have of late considerably increased the usefulness of $x$ rays in the diagnosis of affections of the intestinal tract. This improvement is chiefly due to the use of large doses of bismuth as employed by Rieder, Holtzknecht, and others combined with the more recent method of introducing air into the stomach and large intestine. The injection of air markedly increases the translucency of the abdomen, so that abnormal shadows such as those caused by tumours, concretions of the appendix, \&c., can be recognised and in many cases it is possible to obtain by means of an x ray examination definite evidence of the cause of many of the hitherto obscure abdominal conditions.

When bismuth suspended in fluid is swallowed the progress of its opaque shadow as it passes down the osophagus is readily seen on the fluorescent screen, and any obstruction due to stricture, pouches, foreign bodies, or tumours as readily detected. On reaching the stomach the bismnth passes at once to the most dependent point, and if the stomach is empty gradually spreads towards the pylorus and upwards to the cardiac end. If food is already present in the pyloric portion the bismuth is retained at the cardiac end until the pyloric becomes empty.

Dilatation and gastroptosis are recognised by changes in the size, shape, and position. Fig. 1 is a tracing of one of the common varieties of normal stomach. Fig. 2 shows a case of dilatation and gastroptosis admitted to Guy's Hospital under the care of Mr. C. J. Symonds. On opening the abdomen an old dnodenal ulcer with contraction was found, and this was excised, together with part of the stomach. In mapping out the stomach it is necessary that the patient be examined in the upright position, as a greatly dilated stomach may appear of normal size when it is examined with the patient lying down. Frequently definite symptoms of dilatation accompanied by many of the recognised physical signs have occurred in cases in which 
$x$ ray examination and subsequent exploratory operation have shown that the stomach was normal. In many of the cases of ptosis of the stomach or colon roluntary contraction of the abdominal muscles will be found sufficient to raise the viscera to the normal position. A rise of three or four inches is not uncommon and indicates a trial of treatment by massage and regulated exercises. The results of this treatment or of the support obtained from an abdominal belt are ascertained by a screen examination. In the same way the after results of operation can be ascertained. In several cases where a gastro-enterostomy had
Fis.1.
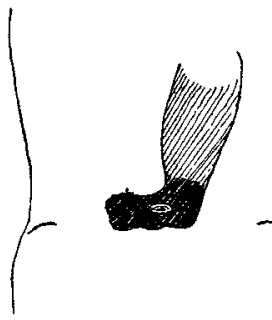

Fig. 2.

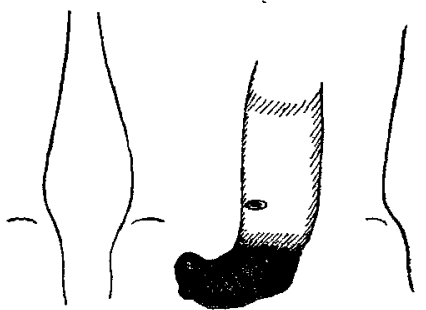

FIG. 1.-Tracing of normal stomach after a bismuth meal. FIG. 2.-Dilatation and gastroptosis.

been performed I have seen the bismuth passing through the artificial opening, and in one of these the bismuth reached the cæcum in one and a half hours instead of in the normal four to five hours, showing that the new opening was patent and the food passing by the short circuit.

Hour-glass contraction is detected by the marked alteration in shape, as is shown in Fig. 3. In this case the sharp indentation suggested the possibility of a tumour pressing on the greater curvature of the stomach, but on injecting air into the colon no abnormal shadow was seen. Mr. F. J. Steward verified the diagnosis of hour-glass stomach and performed a gastro-jejunostomy. A normal appearance greatly resembling hour-glass contraction is occasionally observed, especially when the bismuth meal has not sufficiently distended the organ. Fig. 4 shows a well-marked example of this.
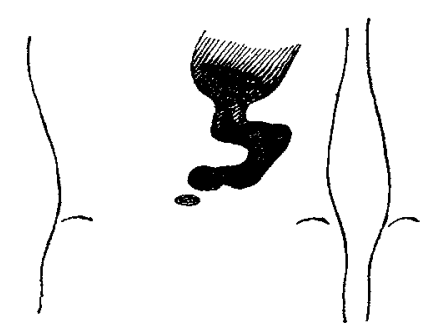

Fis.3.

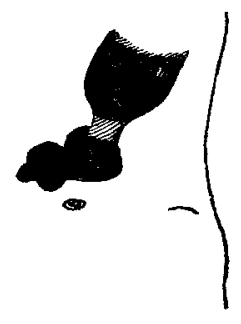

Fig. 4 .
FrG. 3.-Hour-glass stomach.

FIG. 4.-Normal separation of cardiac and pyloric portions.

A diagnosis of hour-glass contraction was made from the $x$ ray appearance, but Mr. R. P. Rowlands found the stomach to be normal and the symptoms due to duodenal contraction. While performing the operation of gastro-jejunostomy he observed the stomach to contract and again relax, giving exactly the appearances seen on the fluorescent screen. I have recently had several cases showing in a less marked degree the same normal separation of the cardiac and pyloric portions.

In gastric ulcer without contraction I have not found that the rays are of service in diagnosis. Cases have been described in which the bismuth could be seen clinging to the roughened surface of the ulcer but I have not met with an instance of this. Possibly air injection into the stomach after the bismuth has passed the pylorus will prove of use in these cases.

Tumours in the region of the stomach can sometimes be detected by the use of air injections. I have employed the method in 10 cases of suspected abdominal tumour. Definite abnormal shadows were visible in three cases, in two of which tumours corresponding to the $\mathrm{x}$ ray appearance were found on operation. The third case was discharged from hospital without operation. In seven cases no tumour was visible; three were discharged without operation and in the others the symptoms were found to be due to hour-glass contraction, duodenal stenosis, appendicitis without a concretion, and carcinoma of the pylorus. In the last case the carcinoma affected a large part of the stomach. A bismuth meal was given and air was injected into the colon. No shadow of the tumour was seen, but part of the bismuth was retained in the stomach 24 hours later, showing that there was some obstruction about the pylorus. Probably an injection of air into the stomach would have shown the tumour in this case.

Fig 5, from a tracing on the fluorescent screen, shows the appearances seen in a case of carcinoma of the pylorus after outlining the stomach with bismuth and distending the colon with air. The dense shadow of the vertical stomach was displaced to the left and a large faintly outlined shadow could be seen lying behind the umbilicus. At the operation this was found by Mr. L. A. Dunn to be due to a carcinoma of the pylorus involving a great part of the greater curvature of the stomach and a portion of the transverse colon. A similar appearance is shown in Fig. 6. The shadow of a swelling
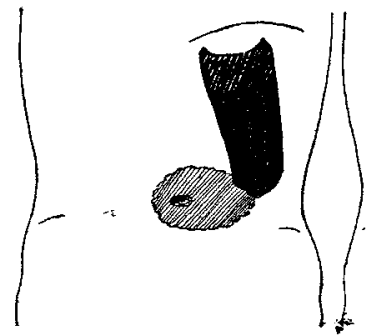

fig. 5.

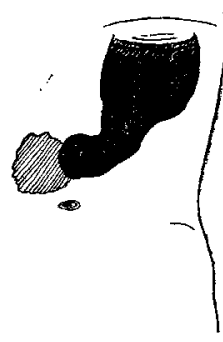

Fig.6.
Fig. 5.-Carcinoma of pylorus.

FIG. 6.-Thickening round pyloric ulcer. Appearances shown after a bismuth meal and air injection of colon.

was seen surrounding the pylorus and this was found by Mr. Rowlands to correspond to a thickening round a large anterior pyloric ulcer which was adherent to the abdominal wall. In both cases gastro-jejunostomy was performed.

In stenosis of the pylorus dilatation of the pyloric portion with delay in the passage of the bismuth meal and occasionally an increase in peristalsis are met with. It is at present doubtful how much reliance can be placed on any of these symptoms. In duodenal stenosis I have frequently found that all were absent.

The bismuth meal employed in these examinations consists of from one to two ounces of carbonate of bismuth suspended in a pint of bread-and-milk or mixed with ordinary food. The subnitrate salt is reported to give rise to symptoms of nitrite poisoning in some cases. The carbonate, however, is quite safe and I have given it in doses of from two to three ounces in over 100 cases without ill-effect and without producing constipation. Much more accurate information is obtained from the bismuth meal than from the older methods of passing opaque bougies or giving small doses of bismuth in water or capsules.

The best method of introducing air is by using an ordinary Higginson's syringe. For the stomach the nozzle of the syringe is attached to a stomach tube previously introduced. No uncomfortable symptoms need be caused as the amount of air injected is under control and the effects can be watched on the screen.

On leaving the stomach the bismuth becomes so diffused in the small intestine that little information can be obtained. If, however, there is obstruction at any part the bismuth can be seen to collect above the constricted point. The first part of the meal usually reaches the cæcum in a healthy person in about four and a half hours, but it is frequently delayed until six hours or more. The size and position of the cæcum are readily ascertained by filling it with bismuth either from a meal or by a bismuth enema. Occasionally it is found low in the pelvis even in apparently healthy individuals, but in these it is always freely moveable on respiration. Its size, degree of fixation, and the length of time the bismuth is retained are the chief points of importance in diagnosis.

Cases have been recorded in which tumours in the pelvis: and concretions in the vermiform appendix have been demonstrated by the rays after an air injection. Professor Goldmann ${ }^{2}$ of Freiburg recently described his method of air injection at the Royal Society of Medicine and showed skiagrams of some cases of tumour and abscess of the abdomen and of concretions in the appendix. By injecting

1 Goldmann : Proceedings of the Royal Society of Medicine, vol.i.s 
air per rectum the whole length of the large bowel up to the ileo-cæcal valve becomes translucent to the rays, and the effect of this, especially on the pelvis, is very pronounced. If concretions in the appendix can be demonstrated with certainty the method will be of great value in deciding the question of operation during the quiescent period. I have found that fairly translucent objects such as fæces in the colon are visible and therefore the comparatively opaque concretions should be easily demonstrated. In the few cases I have examined with air injection no opacity was shown by the rays and no concretion was found on subsequent operation.

Acute obstruction of the large bowel is best detected and localised by a bismuth enema. In the more chronic forms with incomplete obstruction from growths and stricture, and in the various forms of constipation a bismuth meal gives the more accurate information. The meal should be given about 28 hours before the $\mathrm{x}$ ray examination. In this time most of the bismuth will have passed in a normal person to the descending colon and the cæcum and transverse colon have become comparatively empty. The normal appearance at this time is shown in Fig. 7. If the condition of the stomach also requires investigation a second bismuth meal is now given and this organ examined. If necessary subsequent daily examinations can be made to ascertain the nature of the delay and the length of time the bismuth is retained at any point.

Obstruction of the large bowel sometimes causes greatly increased peristalsis and the bismuth is hurried along until it reaches the constricted point. I have observed this to occur in some cases of impacted fæces and in two cases of carcinoma of the sigmoid Hexure. In one of the latter admitted to Guy's Hospital with a history of six months' "constipation the bismuth reached the splenic flexure in six hours (Fig. 8) and in 28 filled the whole of the large bowel to

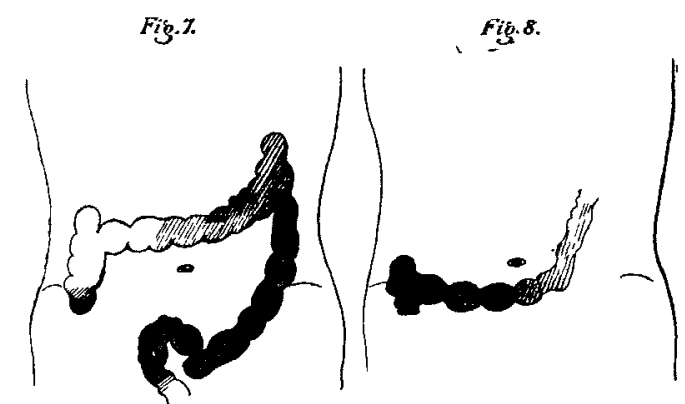

IG. 7.-Normal appearance of colon 28 hours after a bismuth meal Frg. 8.-Obstruction from carcinoma of sigmoid flexure.; Appearances at six hours.

the lowest part of the sigmoid flexure. Recurrent spasms with rapid waves of peristalsis, accompanied occasionally by great contraction of the lumen of the bowel throughout its whole length, were repeatedly observed. Waves of peristalsis followed by retro-peristalsis could be seen driving the bismuth backwards and forwards and producing at the sigmoid flexure a regular churning movement with rapid changes in its shape. During the spasms the contracted bowel could lo felt through the abdominal wall. Belladonna was given to relieve the spasm and pain and the patient was examined two days later. The whole of the large intestine was then ying motionless and greatly distended with fæes and gas.

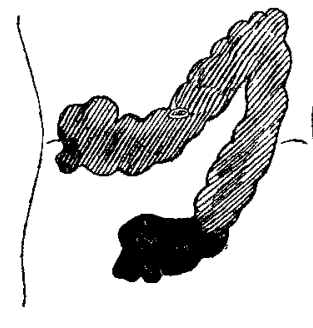

$F / 39$

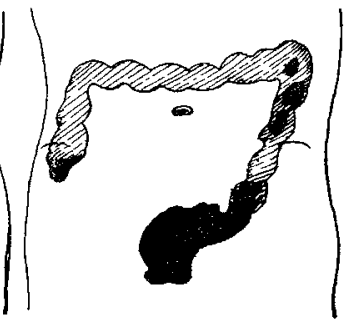

Fig. 10.
FrG. 9.-Obstruction from carcinoma of sigmoid flexure. Appearances at four days.

Fra. 10. - Case of partial occlusion of sigmoid flexure from carcinoma, 18 hours after bismuth meal.

None of the bismuth had reached the rectum. The appearance on the fourth day is shown in Fig. 9. The characteristic $x$ ray appearances showed that there was an obstruction at the lower part of the sigmoid flexure. Mr. C. H. Golding-Bird operated and found a small carcinoma encircling and occluding the sigmoid flexure immediately above the rectum.

In another case admitted under the care of Mr. W. Arbuthnot Lane the symptoms were less pronounced. The patient, a man, aged 68 years, who was "always constipated," had suffered from a severe attack four months previously, the constipation then lasting a week. For 16 days before the $x$ ray examination the bowels had not acted, although croton oil and numerous enemata had been given. A bismuth meal was found to pass through the large intestine very quickly, and in 18 hours most of it was found retained in the iliac colon and sigmoid flexure (Fig. 10). In spite of fairly active peristal sis the rectum remained clear and the obstruction was evidently due to a constriction at the lower part of the sigmoid flexure. $\mathrm{Mr}$. Lane found a small carcinoma encircling the bowel at this point.

Retention of the bismuth at or about the splenic flexure is frequently seen, and in some cases this is apparently due to kinking of the colon at this point. In a case of severe chronic constipation in which $\mathrm{Mr}$. Lane subsequently performed colectomy a marked narrowing of the last part of the transverse colon was observed. In 48 hours the bismuth had not reached the splenic flexure but was retained in a greatly distended cæcum and ascending colon (Fig. 11). On re-examination four days after the meal was taken some of the bismuth had passed to the siomoid flexure but a large part was still retained in the distended cæcum. Fig. 12, from a

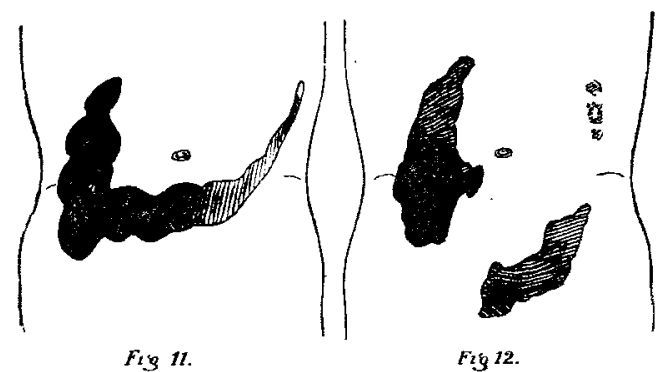

FIG. 11.-Case of chronic constipation. Appearances at 48 hours FrG. 12.-Case of chronic constipation. Appearances at four days.

skiagram taken four days after the bismuth meal, shows the enlarged cæcum and ascending colon distended by the bismuth meal and the comparatively small portion that had passed into the iliac colon and sigmoid flexure.

The normal times and $x$ ray appearances at the various stages of the passage of a bismuth meal were ascertained in an investigation undertaken with Dr. A. F. Hertz ${ }^{2}$ on "the passage of food along the human alimentary canal." Subsequently a number of cases of constipation were examined and the results, with details of the cases, given by Dr. Hertz ${ }^{3}$ in a paper on Chronic Constipation read at the Royal Society of Medicine. Impaction of fæces in the sigmoid flexure and rectum and loss of contractile power of the large bowel were found to be frequent causes.

In constipation the method is of value in showing the part of the bowel in which the delay occurs, and in some cases the cause of the condition, and in indicating the proper lines of treatment. The immediate effects of the various aperients and enemata and the after-results of the different methods of treatment can also be ascertained by means of the bismuth meal and $x$ ray examination.

Welbeck-street, $\mathrm{W}$.

2 Hertz: Guy's Hospital Reports, vol. lxi., and Brit. Med. Jour., Jan. 18th and 25th, 1908

3 Proceedings of the Royal Society of Medicine, February, 1908.

An English Surgeon Murdered in Pahang.The Times Singapore correspondent, in a telegram dated July 21st, says: "A gang of 15 Chinese attacked Mr. Barrack, a district surgeon, and a contractor near the Gambang resthouse in the Kwantan district of the Pahang State on the 15th of the month. Mr. Barrack was killed. The murderers escaped, taking with them $\$ 8000$ (£933)." Mr. J. W. Barrack, M.B., Ch.B. Edin., was late house surgeon to the General Hospital, Singapore, and previously served in a similar capacity to the Seamen's Hospital at the Royal Victoria and Albert Docks. 